\title{
POLARITY OF Q-BURSTS
}

\author{
Toshio Ogawa1) \\ Science Laboratory International ${ }^{2)}$
}

\begin{abstract}
ELF transient signals were observed by using a triggering technique at Aso, Kyushu for 6 days in August 1977, and Q-bursts were examined with a special attention to their polarity. It was found that $85 \%$ of 327 selected bursts were of negative polarity and $15 \%$ of positive polarity. The Q-factor of the Earth-lonosphere cavity resonances was estimated as $6.52 \pm 1.01$ from 26 clear Qbursts of exponential decay. At last importance of the $\mathrm{Q}-$ burst study is pointed.
\end{abstract}

Key words: ELF, Schumann resonance, Q-burst, Q factor, Sprite, Positive discharge

\section{Introduction}

The Q-bursts have been studied in the past as follow. In the 1950's the Earthionosphere cavity resonances were predicted by Schumann (1952) and efforts were made to detect the ELF resonance phenomena. The transient but resonance oscillations were noticed as such phenomena. In the 1960's the Schumann resonances were measured clearly and discussed in relation to global thunderstorm activity. A beautiful large-amplitude transient resonance oscillations at about $8 \mathrm{~Hz}$ were recorded at 080137.6GMT May 8, 1966 at Kyoto (Geomagnetic $24.5^{\circ} \mathrm{N}, 202.2^{\circ} \mathrm{E}$ ) and was called the Q-burst by Ogawa et al. (1966). This special Q-burst was soon found to have occurred in global scale, namely at Aso $\left(22.1^{\circ} \mathrm{N}, 198.1^{\circ} \mathrm{E}\right)$, Palo Alto $\left(43.5^{\circ} \mathrm{N}, 299.0^{\circ} \mathrm{N}\right)$, Kauai $\left(21.7^{\circ} \mathrm{N}\right.$, $265.6^{\circ} \mathrm{E}$ ), and Kerguelen Island $\left(56.5^{\circ} \mathrm{S}, 127.8^{\circ} \mathrm{E}\right.$ ) (Ogawa et al., 1967). To the 1970 's Jones and his co-workers (e.g. Jones and Kemp, 1971) made analyses of Qbursts to explain how they originate from lightning discharges, while Galejs (1972) published a comprehensive textbook of ELF propagation. The 1980's were a relatively calm decade for ELF study, but perhaps Bliokh (e.g. 1980) and Sentman (1983) continued to work on the Schumann resonances theoretically and experimentally. The 1990's were the decade of regeneration of the Schumann resonances including Q-bursts, when Williams and his co-workers (e.g. Boccippio et al., 1995) discovered their relation with sprites, the upper atmosphere optical events caused by lightning CG (Cloud-to-Ground) discharges. The sprites brought a remarkable attention to the positive $\mathrm{CG}$ discharges which originate at a stratus part of thunderstorm cloud. At last the 2000's may be a new era to work out the mechanism of such positive CG discharges, quite different from the

1)Also associated with Kochi University.

2)1-12-12-2C Kamobe, Kochi 780-8052. e-mail:ogawasli@i-kochi.or.jp 
normal negative CG discharges, to produce the sprites and related various phenomena, and the $\mathrm{Q}-$ bursts.

The Q-burst was named by the following two Q-related reasons (Ogawa et al., 1966; Handa et al., 1971). First, it is a Quiet (=approximately no VLF) EM resonance burst in the Earth-ionosphere cavity, and second, the $Q$-factor of the cavity resonances can be estimated from a single damped oscillation of the $\mathrm{Q}^{-}$ burst.

It is the purpose of this paper to examine ELF burst data obtained in 1977. left unanalyzed to date, comparing with previous results and to discuss the importance of Q-burst study.

\section{Measurements and data selection}

The ELF bursts were measured in the following way. (1)The experimental period was 6 days from August 5 to 10,1977, at Aso, Kyushu. (2)A ball antenna was used to measure the electric vertical component. (3)The triggering technique was first applied to detect individual bursts of larger amplitude than a certain limited value. (4)A pen recorder was used with the overall frequency response of $3.8-28 \mathrm{~Hz}$. Advantage of using such a low pass system was to detect Q-bursts clearly.

The 1,252 transient events were recorded during 2,770 minutes, the frequency of occurrence of the bursts being 0.45 events per minute. They included, however, some numbers of artificial noises. Then 327 good samples were selected to be analyzed, that equivalents to one sample selected every eight minutes. The data selection criteria were as follow. (1)The waveform was beautiful at first glance. (2)The quasi-sinusoidal oscillations had three or more amplitude peaks. (3)The damping coefficient $\Omega$ could be estimated in the form $\left(e^{-\Omega t} \cos \omega t\right)$, from which the Q-factor of the resonances in the Earth-ionosphere cavity could be estimated. (4)The near $8 \mathrm{~Hz}$ and $14 \mathrm{~Hz}$ events were counted as a result.

The number of burst data are summarized in Table 1.

Table 1. Burst data summary

\begin{tabular}{|c|l|}
\hline Nos. of data & \\
\hline 26 & Used to estimate $\Omega$ and $Q$. \\
116 & Tested for evaluation of $\Omega$. \\
327 & Good samples selected. \\
1,252 & Recorded. \\
\hline
\end{tabular}

Examples of Q-bursts of negative polarity and of positive polarity are shown in Figs. 1(a) and (b), respectively. The samples of good shape are selected for each polarity. 


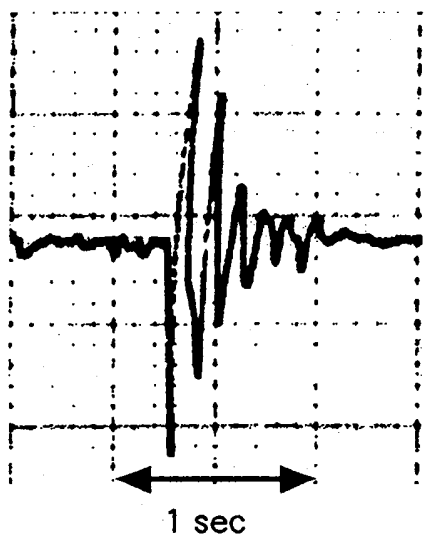

(a)

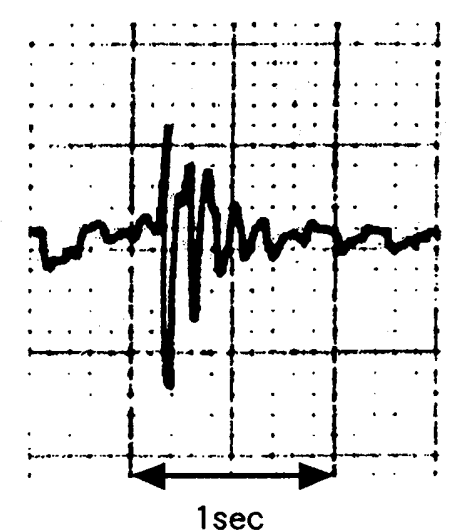

(b)

Fig. 1. Typical Q-bursts of negative polarity(a) and of positive polarity(b). Amplitude is shown in arbitrary scale.

The characteristics of the waveforms should be pointed are first rapid excursions to the negative side or to the positive side, and the amplitudes decreased exponentially with time to the amplitude level of background noises.

\section{Results}

Of the 327 selected bursts 277 (84.7\%) were of negative polarity and 50 (15.3\%) were of positive polarity. The histograms of burst amplitudes of negative polarity and of positive polarity are shown in Fig. 2, where the first half amplitudes of the oscillations were measured. The position of the peak of the occurrence distribution

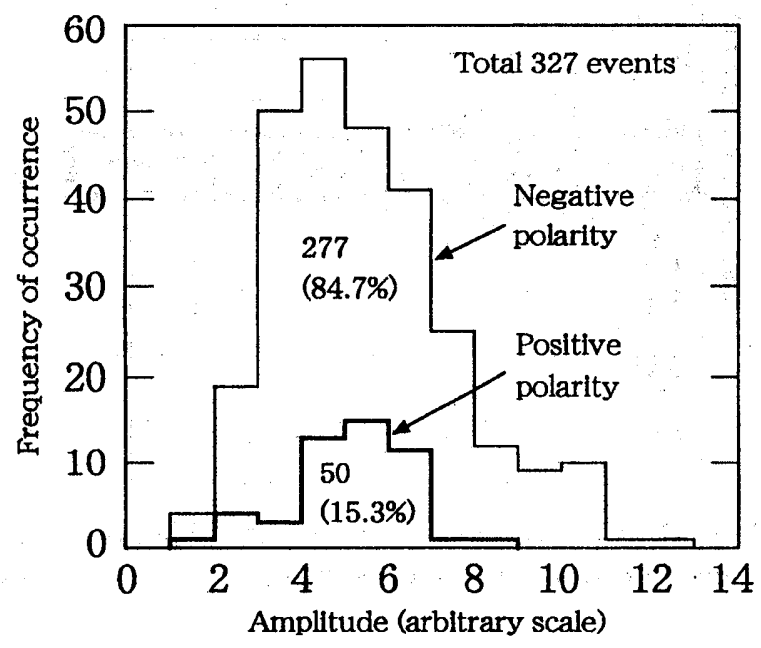

Fig. 2. Histograms of burst amplitudes of negative and positive polarities. 
of negative polarity is at 4-5 in arbitrary scale, smaller than 5-6 of positive polarity, but it is difficult to consult more with the fact.

The definitive difference between the negative and positive polarity $Q$-bursts shown in Fig. 2 is the predominance of large amplitude part between 9-13 in the negative polarity bursts. There is no such distribution in the positive polarity bursts.

The reason to have measured the first impulses of the oscillations to make the histograms in Fig. 2 is that they would represent activity scale of lightning to produce the concerned bursts. The burst oscillations of negative polarity look generally more beautiful than those of positive polarity as shown in Fig. 1.

The Q-burst has so beautiful oscillations that the damping coefficient $\Omega$ could be estimated in the form $e^{-\Omega t} \cos (\omega t)$. The $Q$-factor of the resonances in the Earth-ionosphere cavity could then be estimated as $Q=6.52 \pm 1.01$ from the damping coefficient $\Omega=5.11 \pm 0.84$ by using 26 selected $Q$-burst oscillations after testing 116 samples by using the relation $\mathrm{Q}=\omega_{\mathrm{O}} / 2 \Omega$ where $\omega_{\mathrm{O}}$ is the resonance angular frequency (Handa et al., 1971).

A model of vertical electric field of Q-burst in the 1970's except of the initial pulse portion was constructed as shown in Fig.3, where the resonance frequency of $7.72 \mathrm{~Hz}$ (Ogawa et al., 1979) is used. The amplitude levels of background noises are shown by the thick rectangular box.

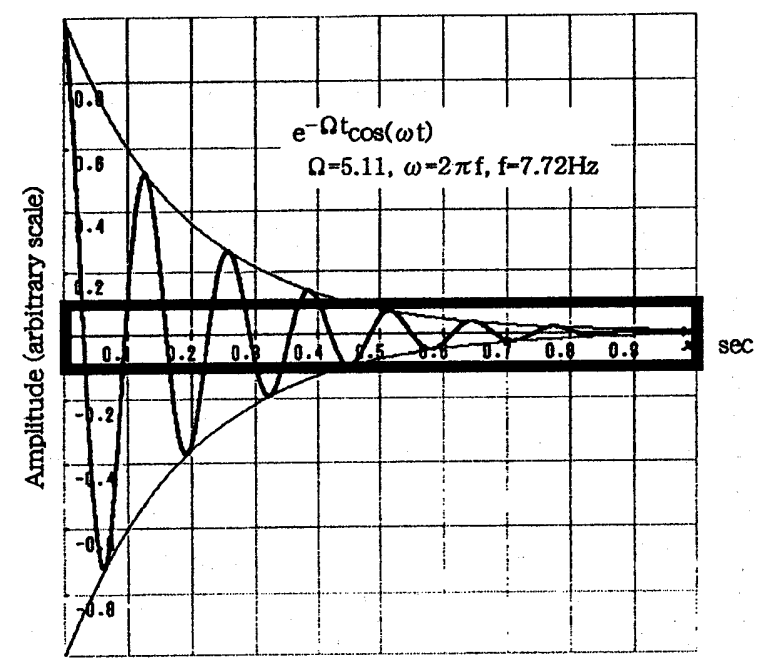

Fig.3. A model of Q-burst oscillations except of initial pulse portion in the1970's.

Background amplitude levels are shown by the thick rectangular box.

\section{Discussions}

The $84.7 \%$ of 327 selected transient bursts had initial pulses that went down to 
the negative side. This means that positive charges were removed from the cloud to the ground. This kind of discharges is called positive discharges. The lightning discharges are commonly observed as negative discharges, which are produced by negative charges removing from the cloud base to the ground. As a result the $\mathrm{Q}$-bursts were produced more often by positive discharges than negative discharges. This percentage of occurrence is comparable with the percent of Jones and Kemp (1971), in which $85 \%$ of selected events for analysis and $66 \%$ out of several thousand recognizable events were of negative polarity.

The charge moment changes of source discharges were estimated by Jones and Kemp (1971) to be as large as $4 \times 10^{3} \mathrm{C} \cdot \mathrm{km}$. In the present case the oscillations having three or more amplitude peaks were selected as the $\mathrm{Q}-$ bursts. The $\pm 5 \%$ of the amplitude from the base line shown by the region marked with thick rectangular box in Fig. 3 is to be background noises, then three or four amplitude peaks were detected. This means that the $\mathrm{Q}$-bursts were larger than the background noises by a factor of 20 .

In the recent work by using lightning data of NLDN (National Lightning Detection Network) Boccippio et al. (1995) found that the origin of Q-bursts was positive CG discharges, with which sprites were associated. The cloud system to produce such positive discharges is called MCS (Mesoscale Convective System) (Shepherd et al., 1996). This kind of cloud system might be also seen in winter Japan Sea thunderstorms (Kawasaki 2001; Fukunishi et al., 2001), and in winter thunderstorms over the Pacific Ocean along the cold front (Fukunishi, et al., 2001).

Handa et al. (1971) measured five components of ELF electric and magnetic bursts at Aso in 1968 and estimated the damping coefficients of the Q-bursts as $\Omega_{\mathrm{EV}}=4.96, \Omega_{\mathrm{NS}}=6.27$, and $\Omega_{\mathrm{EW}}=4.87$, where $\mathrm{EV}$ gives the vertical electric component, and NS and EW give the components along the propagation directions (north-south and east-west), respectively. By these values was proved anisotropic propagation of ELF in the Earth-ionosphere waveguide. The damping coefficient $\Omega=5.11 \pm 0.84$ was obtained for the vertical electric component in the present study, which complements and perhaps confirms the previous results of Handa et al. (1971).

The Q-factor from the first mode oscillations in the Schumann resonances was estimated as $\mathrm{Q}=6.52 \pm 1.01$ in the present study. This is comparable value with $\mathrm{QEV}_{\mathrm{E}}=6.72$ obtained by Handa et al.(1971) where $\mathrm{Q}_{\mathrm{NS}}=5.32$ and $\mathrm{Q}_{\mathrm{EW}}=6.85$ were also obtained. These values of the $\mathrm{Q}$-factors are about twice larger than the value $\mathrm{Q}=3.3$ estimated from the ratio of the resonance frequency to the half-power band-width of the spectrum (Ogawa and Tanaka, 1970). The latter used the commonly-used method to estimate the $\mathrm{Q}$-factor, but it is proved not adequate to 
estimate the $\mathrm{Q}$-factor of the Schumann resonances. This is because the approximation of $\Delta \mathrm{f}_{\mathrm{O}} / \mathrm{f}_{\mathrm{O}} \ll 1$ used in the method should not be applied for such low frequencies of Schumann resonances, where $\mathrm{f}_{\mathrm{O}}$ is the resonance frequency and $\Delta \mathrm{f}_{\mathrm{O}}$ is the frequency band width at the half power of the spectrum.

\section{Conclusions}

The characteristics of Q-bursts obtained in this study are summarized and importance of the Q-burst study is pointed as follow.

1. The Q-burst is a short-time event within a second, and their occurrence frequency is high, may be one every eight minutes.

2. The first pulse of the $\mathrm{Q}$-burst gives the lightning character as a source of the burst. Close examination of the first pulses of Q-bursts is left for study in the future work.

3. The damping coefficient in the exponential decay of the Q-burst was obtained as $\Omega=5.11 \pm 0.84$ in average, and the Q-factor estimated from the coefficient was $\mathrm{Q}=6.52 \pm 1.01$. They are the most representative character of the Earth-ionosphere cavity. These numbers are the key characters to understand how fast the EM energy introduced by lightning discharges will dissipate within the wall of the Earth-ionosphere cavity or from the cavity to outside.

4. The Q-bursts are related with the most interesting lightning-related phenomena; the positive CG discharges which are not yet understood fully, and with upper atmosphere optical events represented by sprites which will offer the most interesting topic to be studied in this decade.

Acknowledgements. The author thanks Earle Williams, MIT for his valuable suggestions and discussions on this work presented at the IAGA-IASPEI2001 Vietnam Assembly. Many thanks are also due to my colleagues H. Hagino, at PoliTech College, Kochi and M. Komatsu, Amana Inc., LTD for their help during the course of this study.

\section{References}

Bliokh, P. V., A. P. Nicholaenko, and Yu.F. Filippov, Schumann resonances in the Earth-ionosphere cavity, Ed. by D. L. Jones, 168 pp., P. Perigrinus, Oxford, New York, 1980.

Boccippio, D. J., E. R. Williams, and S. J. Heckman, Sprites, Q-bursts and positive ground strokes, Science, 269, 1088, 1995.

Fukunishi, H., Y. Takahashi, T. Adachi, and R. Miyasato, Characteristics of sprites and elves observed in winter above Japan, p.98 in Abstracts of the IAGA-IASPEI Joint Scientific Assembly, Vietnam, 2001. 
Galejs, J., Terrestrial Propagation of Long Electromagnetic Waves, Pergamon Press, Oxford, pp.362, 1972.

Handa, S., T. Ogawa, and M. Yasuhara, Damping coefficients of Q-type bursts in the Schumann resonance range, Contributions, Geophys. Inst., Kyoto Univ., 11, $11-15,1971$.

Jones, D. L. and D. T. Kemp, The nature and average magnitude of the sources of transient excitation of Schumann resonances, J. Atmos. Terr. Phys., 33, 557$566,1971$.

Kawasaki, Z., Positive CG during winter thunderstorms and its possible charge distribution, Abstracts, IAGA-IASPEI Joint Scientific Assembly, Vietnam 2001, p.101, 2001.

Ogawa, T. and Y. Tanaka, Q factors of the Schumann resonances and solar activity, Special Contributions, Geophys. Inst. Kyoto Univ., 10, 21-28, 1970.

Ogawa, T., Y. Tanaka, T. Miura, and M. Yasuhara, Observations of natural ELF and VLF electromagnetic noises by using ball antennas, J. Geomag. Geoelectr., 18, 443-454, 1966.

Ogawa, T., K. Kozai, H. Kawamoto, M. Yasuhara, and H. Hujita, Schumann resonances observed with a balloon in the stratosphere, J. Atmos. Terr. Phys., 41, 135-142, 1979.

Ogawa, T., Y. Tanaka, M. Yasuhara, A. C. Fraser-Smith, and R. Gendrin, Worldwide simultaneity of occurrence of Q-type ELF burst in the Schumann resonance frequency range, J. Geomag. Geoelectr., 19, 377-384, 1967.

Schumann, W. O., Uber die Dampfung der elektromagnetischen Eigenschwingungen des Systems Erde-Luft-Ionosphare, Z. Natureforsch., 7A, 250-252, 1952.

Sentman, D. D., Schumann resonance effects of electrical conductivity perturbations in an exponential profile, J. Atmos. Terr. Phys., 45, 55-65, 1983.

Shepherd, T. R., W. D. Rust, and T. C. Marshall, Electric fields and charges near 0 ${ }^{\circ} \mathrm{C}$ in stratiform clouds, Monthly Weather Review, 124, 919-938, 1996.

(Received December 3, 2001; revised January 10, 2002; accepted January 28, 2002) 